\title{
MORTE E MORRER EM TEMPOS DE COVID-19
}

\section{DEATH AND DYING IN TIMES OF COVID-19}

\author{
José Roberto Goldim¹, Márcia Santana Fernandes ${ }^{1}$
}

\begin{abstract}
RESUMO
A pandemia da COVID-19 está tendo impactos em toda a sociedade humana. Muitas questões antes abordadas no plano individual pela Bioética agora tem o desafio de ter o seu enfoque ampliado para toda a sociedade. É uma grande provocação que as diversas áreas estão buscando responder adequadamente em meio a cenários desconhecidos ou incertos. A reflexão sobre os temas envolvidos nas questões da morte e do morrer são fundamentais e devem ser realizadas.
\end{abstract}

Palavras-chave: Bioética; morte; direito a morrer; futilidade médica

\section{ABSTRACT}

The COVID-19 pandemic is having an impact on human society as a whole. Many issues previously addressed at the individual level by bioethics now face the challenge of having their focus expanded to the society level. It is a great challenge that different areas are trying to adequately respond to in the midst of unknown or uncertain scenarios. Reflecting on the topics involved in the issues of death and dying is crucial and must be carried out.

Keywords: Bioethics; death; right to die; medical futility

\section{O IMPACTO DA MORTE}

A pandemia da COVID-19 colocou toda a população mundial em uma situação de vulnerabilidade nunca vista anteriormente. Nem a pandemia de influenza, em 2009, trouxe tamanha sensação'. Não há refúgio seguro. Talvez o maior medo associado à pandemia da COVID-19 é a morte.

O número de mortos foi crescendo e acabou assumindo valores impressionantes. No início da pandemia, os números da China eram temidos. A China, ao longo de toda a pandemia, teve pouco mais de 4,8 mil pessoas mortas. Neste período mesmo período, no Brasil morreram mais de 250 mil pessoas e no mundo 2,5 milhões de pessoas ${ }^{2}$.

Estes valores, que inicialmente assustavam a todos, com o passar do tempo e a continuidade do crescimento, foram sendo banalizados quanto ao seu impacto. A Lei de Shannon, proposta em 1948, para explicar matematicamente os processos de comunicação, pode ser útil para buscar um melhor entendimento. Esta lei propõe que existe uma relação inversamente proporcional entre o impacto de uma informação e a sua frequência. Ou seja, na medida em que a frequência de uma informação aumenta, o seu impacto inicial diminui ${ }^{3}$. As informações sobre as mortes ocorridas, que antes geravam discussões e ansiedade, que eram personalizadas, passaram a ser apenas dados que se acumulam. Nos telejornais este número é uma mera atualização diária de um terrível placar, mas que é rápida, e na maioria das vezes, insensivelmente, transmitido. O comentário de Kurt Tucholsky, feito primeiramente em uma publicação de 1925, ainda sob o impacto das mortes ocorridas na primeira guerra mundial - "A morte de uma pessoa: é uma catástrofe. 100 mil mortes: isso é uma estatística!" - é de uma atualidade impressionante ${ }^{4}$.

Clin Biomed Res. 2021;41(1):95-99

1 Laboratório de Pesquisa em Bioética e Ética na Ciência (LAPEBEC), Hospital de Clínicas de Porto Alegre (HCPA). Porto Alegre, RS, Brasil.

Autor correspondente: José Roberto Goldim jgoldim@hcpa.edu.br Laboratório de Pesquisa em Bioética e Ética na Ciência, Hospital de Clínicas de Porto Alegre Rua Ramiro Barcelos 2350, Bloco C, 6 andar 90035-903, Porto Alegre, RS, Brasil. 


\section{A MORTE E A SITUAÇÃO DE RECUSOS ESCASSOS}

Muitos temas associados à morte exigiram reflexão e esclarecimento ao longo da pandemia. A reflexão passa pela necessidade de ter que alocar recursos escassos. Os processos e os critérios de triagem de pacientes foram pensados, inicialmente, para situações de medicina de guerra e de catástrofes ${ }^{5}$. São processos que visam o bem de conjunto um de pessoas, e não de cada pessoa em particular. Em várias publicações leigas e científicas ocorreram ambiguidades e confusões na utilização de conceitos essenciais à sua compreensão adequada.

A utilização de critérios defensáveis, desde o ponto de vista técnico, ético e social, para a alocação de recursos escassos, foi uma necessidade para o enfrentamento de situações críticas ocorridas durante a pandemia em diferentes regiões ou países.

A utilização isolada de critérios demográficos, como a idade dos pacientes, que serviu de base para a alocação de leitos de Unidades de Tratamento Intensivo (UTI), foi extremamente criticada. Este critério foi discriminatório ao transformar uma diferença etária em desigualdade de acesso. Foi supostamente um critério utilitarista utilizando uma medida teórica e despersonalizada como o critério Qualy, ou seja, anos de vida com qualidade. A idade, assim como qualquer outro critério isolado, é sempre questionável ${ }^{6}$.

Por outro lado, alguns autores confundiram a situação dos pacientes que não tiverem acesso aos recursos necessários com a realização de eutanásia passiva. A eutanásia ocorre quando alguém, muitas vezes um profissional de saúde, intencionalmente abrevia a vida de um paciente. A eutanásia passiva é aquela que ocorre pela não administração de um determinado procedimento terapêutico necessário à manutenção da vida do paciente por motivos de sofrimento insuportável e por solicitação da própria pessoa. Na triagem não há esta intenção de abreviar a vida de alguém em particular, mas sim a de otimizar a utilização de recursos escassos. A intenção de provocar a morte do paciente é fundamental na caracterização da eutanásia.

O objetivo dos processos de triagem é a melhor alocação de recursos escassos, em uma determinada situação específica e dentro dos limites do possível, de acordo com critérios previamente estabelecidos e conhecidos pela sociedade. O paciente e seus familiares não podem ser surpreendidos com a utilização de critérios nunca antes compartilhados e discutidos. É fundamental dar visibilidade aos critérios que serão utilizados no processo de triagem. Isto poderá ser feito por meio da divulgação na própria instituição, por meio de seus canais de divulgação institucional ou pela própria imprensa. O ideal é que toda a rede de saúde utilize critérios iguais e aprovados por instâncias de controle social, ou no mínimo, validadas pelos Comitês de Bioética Clínica das instituições envolvidas.
O que não pode ocorrer é a utilização de processos de triagem, com estes critérios mesmo que divulgados, sem que haja efetiva carência de recursos, ou seja, sem a necessidade de ter que fazer escolhas. Havendo recursos disponíveis, eles devem ser alocados. Não pode haver uma restrição na presunção de uma carência ou necessidade futura. A necessidade e a escassez utilizadas nos processos de tomada de decisão se referem a situações que sempre ocorrem no tempo presente.

Um ponto fundamental nos processos de triagem é não abandonar as pessoas não selecionadas para a utilização dos recursos escassos. Estes pacientes devem receber todos os cuidados paliativos necessários e adequados para minorar o seu sofrimento e desconforto. O bem comum não pode ser entendido como uma desqualificação do indivíduo ${ }^{7}$.

\section{A MORTE E A OBSTINAÇÃO TERAPÊUTICA}

Ao longo dos atendimentos dos pacientes nas UTIs, durante a pandemia, também tem ocorrido situações de obstinação terapêutica. Alguns autores denominam esta situação como sendo Distanásia ${ }^{7}$.

Muitas vezes os próprios profissionais de saúde ou os familiares dos pacientes pressionam por manter cuidados já considerados fúteis ou de implantar outras medidas, progressivamente invasivas, sem que haja a possibilidade de algum benefício associado para o paciente. Muitas vezes os profissionais e familiares se sentem pressionados a utilizar um recurso simplesmente pelo fato dele estar disponível, e não pela sua adequação terapêutica. Conforme propôs Günther Ropohl, em 1981, "não devemos fazer tudo

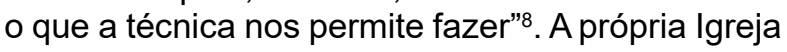
Católica se manifestou, em 1987, neste mesmo sentido: "Mas aquilo que é tecnicamente possível não é necessariamente, por esta mera razão, admissível do ponto de vista moral"s.

\section{A MORTE ADEQUADA}

A adequação na utilização dos recursos tecnológicos na área da saúde é fundamental. Não tem sentido utilizar medidas fúteis. É importante saber reconhecer quando os recursos, que podem beneficiar os pacientes, se esgotam. No momento em que os cuidados paliativos passam a ser exclusivos, é que eles se tornam ainda mais fundamentais.

É extremamente importante manter os familiares e os próprios pacientes, quando possível, informados desta avaliação. Quando todas as medidas terapêuticas de cura se esgotam, permanecem os cuidados paliativos indispensáveis. Um questionamento sempre presente é se foram tomadas todas as medidas que deveriam ser tomadas. Reconhecer o esgotamento de recursos 
terapêuticos de cura é poder afirmar que tudo que podia ser feito foi efetivamente utilizado. Enfatizar esta situação como um esgotamento é mais adequado do que caracterizá-la como um limite, que pode parecer que é uma decisão dependente da equipe assistente, e não uma contingência imposta pela realidade. Ir além é postergar, é prolongar indevida e inadequadamente.

É fundamental que as equipes tenham objetivos e metas terapêuticas claras. Estas informações devem ser compartilhadas entre todos os profissionais envolvidos no atendimento do paciente, com o próprio paciente e seus familiares, além de estar devidamente documentada no próprio prontuário. É fundamental garantir uma morte adequada aos pacientes, isto é, uma adequação em relação a causa, ao modo e ao tempo da sua ocorrência. O morrer adequado é muitas vezes denominado de Ortotanásia. A Resolução 1995/2012 do Conselho Federal de Medicina valida esta maneira adequada de reconhecer o esgotamento dos tratamentos disponíveis para serem utilizados.

A questão dos cuidados paliativos também teve inúmeras utilizações discutíveis. Alguns autores consideraram os cuidados paliativos como sendo eutanásia passiva. Os cuidados paliativos em pacientes em situações próximas da morte têm como finalidade reduzir o sofrimento do paciente. Eles permitem um alívio de seus sintomas e outros desconfortos. Neste conjunto de medidas podem ser incluídos muitas alternativas. Podem ser utilizados medicamentos e procedimentos visando controle da dor. Em situações extremas, podem incluir a realização de sedação paliativa para aliviar a falta de ar e o desconforto em situações de terminalidade. Não é a sedação que acarreta a terminalidade, mas sim permite que o paciente tenha melhor conforto nesta etapa de vida. Os cuidados paliativos não abreviam ou prolongam a morte, mas permitem um cuidado integrado ao paciente.

\section{A MORTE ASSISTIDA}

A morte assistida ocorre quando um paciente solicita ao seu médico que abrevie a sua vida, o que caracteriza a Eutanásia, ou disponibilize meios para tal, que seria o Suicídio Assistido. Em ambas as situações a demanda parte do paciente em relação ao seu médico. Desde o ponto de vista legal, a morte assistida é permitida ou descriminalizada em apenas alguns países ou regiões: Austrália, Bélgica, Canadá, Colômbia, Países Baixos (Holanda), Luxemburgo e Uruguai.

Desde o ponto de vista ético, é importante lembrar que a Associação Médica Mundial mantém a sua posição contrária à participação dos médicos em qualquer forma de eutanásia ou suicídio. $O$ argumento utilizado é que o médico é formado para salvar vidas, mas não para terminar intencionalmente a vida do seu paciente ${ }^{10}$. Na Suíça, houve uma mudança da postura da Academia Suíça de Ciências Médicas em relação ao suicídio assistido. Antes, em 2004, havia uma proibição da participação dos médicos, porém em 2018, assumiram uma postura de permitir. Muitos médicos contestaram esta mudança de posicionamento ético ${ }^{11}$. Na Bélgica ocorreram questionamentos sobre a inclusão da eutanásia como sendo parte dos cuidados paliativos a serem oferecidos aos pacientes ${ }^{12}$.

Com relação a eutanásia, ocorreram situações aparentemente paradoxais. Na Holanda, primeiro país a ter uma legislação específica permitindo a sua realização, houve uma suspensão da realização de procedimentos de eutanásia. A justificativa foi a mobilização dos profissionais de saúde para atenderem as demandas geradas pela pandemia. Uma das instituições mais atuante s na Holanda - Euthanasia Expertise Centre - responsável por mais 898 procedimentos deste tipo em 2019, suspendeu todas as suas atividades durante a pandemia. Os procedimentos de eutanásia foram considerados como eletivos ${ }^{13}$.

Por outro lado, no Canadá, onde $1,6 \%$ dos óbitos são mortes medicamente assistidas, vários procedimentos foram realizados no sentido de atender às solicitações, inclusive, de antecipação de eutanásia. A justificativa utilizada pra realizar e antecipar os procedimentos foi a de evitar que estas pessoas, que já haviam manifestado a sua vontade e que preencheram os critérios estabelecidos pela lei, não corressem o risco de ter COVID-19. Nesta justificativa foram considerados inúmeros fatores, tais como: geração de gastos adicionais ao sistema de saúde; a própria saturação desnecessária dos recursos e instituições; um acréscimo de sofrimento para o paciente e riscos agregados aos seus familiares ${ }^{14}$.

Estas duas posições, contrárias frente a mesma situação, podem ser explicadas em função do foco da decisão e das características culturais de cada um dos países.

Utilizando o referencial de Gert Hofstede, que avalia as culturas nacionais por meio de seis critérios, é possível identificar semelhanças e diferenças entre estes dois países ${ }^{15}$. Algumas destas diferenças podem auxiliar a explicar este aparente paradoxo frente a eutanásia durante a pandemia. Das seis características utilizadas no modelo de Hosftede, os dois países têm semelhanças em quatro e se diferenciam em outras duas. Tanto o Canadá quanto a Holanda têm uma noção de interdependência entre seus cidadãos, e ambos têm culturas individualistas. Estes dois países também são sociedades competitivas, que aceitam um certo grau de risco associado às tomadas de decisão. Contudo, as eles se diferenciam quanto a orientação de longo prazo e a forma como lidam com impulsos e desejos. Os canadenses têm uma orientação mais voltada ao curto prazo, enquanto que os holandeses 
tem uma perspectiva mais longo prazo. Porém quanto aos impulsos e desejos, as perspectivas de invertem. Os canadenses são mais indulgentes em relação aos impulsos e desejos, enquanto que os holandeses são mais restritivos. Isto pode ser a explicação das duas perspectivas. O Canadá ao realizar os procedimentos de eutanásia durante a pandemia reflete esta perspectiva de curto prazo e de valorizar a realização de impulsos e desejos. Por outro lado, a Holanda ao postergar a realização dos procedimentos de eutanásia, revela as suas características de pensar pragmaticamente e a longo prazo. São duas perspectivas aparentemente contraditórias, porém quando avaliadas de forma mais abrangente, ambas mantêm uma coerência com as suas caraterísticas históricas e culturais ${ }^{15}$.

\section{AS MORTES EVITÁVEIS}

As mortes evitáveis são aquelas decorrentes da falta de planejamento adequado no enfrentamento da pandemia, ou até mesmo aquelas decorrentes de decisões que não tem base em conhecimentos técnicos e científicos. Alguns autores denominam estas mortes como sendo Mistanásia ${ }^{16,17}$.

As mortes evitáveis durante a pandemia podem ou não envolver a ocorrência de infecção pelo SARSCoV-2. Muitas outras mortes também deveriam ser também computadas como decorrentes da pandemia, pois foram causadas por situações dela decorrentes. Muitos pacientes morreram, por outras causas, durante a pandemia por falta de assistência adequada. A restrição de procedimentos, de escassez recursos e o despreparo para enfrentar situações como a vivida nesta pandemia, fizeram com que muitos pacientes com COVID-19 e outros sem COVID-19 morressem indevidamente ${ }^{13}$.

Outras mortes evitáveis envolvem situações extremamente delicadas e que merecerão melhor avaliação futura desde o ponto de vista técnico, ético e legal. Na Suécia, várias pessoas que viviam em lares residenciais para idosos tiveram a prescrição de altas doses de sedativos, dadas por médicos que não as conheciam e que nem as viram. Estas prescrições foram dadas por meio de chamadas telefônicas. O objetivo era antecipar mortes que, segundo a avaliação destes profissionais, iriam possivelmente ocorrer. Foram mortes de pessoas que não estavam em estado de terminalidade e foram enquadradas em uma categoria simplesmente em função da sua idade e local de moradia ${ }^{18}$.

\section{A MORTE E A COMUNICAÇÃO COM FAMILIARES}

Inúmeras situações envolvendo problemas de comunicação durante a pandemia também merecem ser comentadas. Estes problemas passam pela comunicação com familiares até questões legais envolvendo a Declaração de Óbito.

O bloqueio de acesso dos familiares às unidades de internação que atendem pacientes com diagnóstico de COVID-19 gerou afastamento para estas pessoas e para os pacientes. São internações longas e com muita tensão associada. O Hospital de Clínicas de Porto Alegre tinha por orientação de nunca fazer uma comunicação de óbito por chamada telefônica. A partir de fevereiro de 2020 começaram a ser pensadas as novas práticas e procedimentos de deveriam ser seguidos na instituição como forma de melhor proteger a todos. Foi uma mudança radical, pois o que antes era fortemente desaconselhado passou a ser a recomendação.

$\mathrm{O}$ afastamento dos familiares dos ambientes hospitalares acarretou a necessidade de se implantar uma nova forma de comunicação com as famílias. Foram criados protocolos e procedimentos visando a adequação das interrelações entre equipes assistenciais e famílias por meio de chamadas telefônicas de áudio e vídeo. Inclusive as notificações de falecimento dos pacientes passaram a ser realizadas desta forma. Os profissionais tiveram uma breve qualificação em procedimentos de comunicação por meio virtual.

Nesta proposta, os familiares receberem notícias diárias do estado de saúde do paciente por um mesmo profissional de saúde. Desta forma, houve uma maior possibilidade do estabelecimento de um vínculo de confiança. Além disto, ocorre também o incremento da relação de confiança que as famílias têm com a instituição. Em função destes fatores, o impacto da comunicação de um óbito ser realizado por chamada telefônica foi bastante minimizado. Muitos familiares, em relatos pessoais, destacaram que se sentiram muito bem acolhidos, mesmo em uma situação tão difícil quanto esta. Estas questões serão objeto de uma publicação específica.

Outra questão envolvendo comunicação foi a possibilidade oferecida de realizar rituais religiosos por meio de chamadas virtuais. Várias lideranças, de diferentes denominações, aceitaram a possibilidade de realizar esta forma de realizarem os atendimentos religiosos. Os familiares também solicitaram que os profissionais fizessem alguma forma de interação religiosa com o paciente. Foram ações importantes no sentido de atender a demandas trazidas em função do sistema de crenças e valores do paciente e de sua família.

A situação envolvendo documentos sobre o óbito de um paciente tiveram uma compreensão inadequada em função da confusão entre suas denominações. Em 1 de março de 2020, o Ministério da Saúde e o Conselho Nacional de Justiça publicaram uma Portaria Conjunta sobre os procedimentos excepcionais para sepultamentos na vigência da pandemia ${ }^{18}$. A imprensa e outros setores confundiram a dispensa da 
Certidão de Óbito dada pelos Cartórios de Registro Civil com a Declaração de Óbito dada pelo médico. Esta mesma Declaração de Óbito é corriqueiramente denominada de Atestado de Óbito. Uma revista de circulação nacional chegou a publicar, em manchete, que foram autorizados os sepultamentos de pessoas sem Atestado de Óbito ${ }^{19}$. Esta medida cartorial visou impedir que os sepultamentos fossem represados, com consequências epidemiológicos. Os familiares têm que realizar todos os procedimentos cartoriais em um prazo de até 60 dias.

\section{CONSIDERAÇÕES FINAIS}

Muitas reflexões éticas ainda serão necessárias para podermos entender a adequação de práticas realizadas durante a pandemia. $O$ despreparo das diferentes instâncias sociais em lidar com situações tão dramáticas como esta apresentada pela pandemia ficou evidente. Os meios de comunicação, os órgãos reguladores do exercício profissional, as instâncias de controle social da saúde e os próprios gestores do sistema, nos seus diferentes níveis, não tiveram respostas adequadas às demandas da população. Muitas vezes os temas envolvendo a morte e a COVID-19 foram abordados de múltiplas e equivocadas formas, desde propostas frias e distantes, apresentando apenas dados burocráticos e estatísticos, até a sua própria espetacularização.

A Bioética tem muito a contribuir para que esta reflexão ocorra de forma abrangente, complexa e interdisciplinar ${ }^{20}$. O importante é manter esta reflexão no plano argumentativo, utilizando os múltiplos referenciais da Ética que podem ser aplicados às situações a serem abordadas. A Ética das Virtudes, das Vontades, dos Princípios, da Responsabilidade, dos Direitos, das Consequências e da Alteridade são excelentes fontes para fazer esta reflexão e verificar a adequação das ações realizadas ${ }^{20}$.

\section{REFERÊNCIAS}

1. Goldim R. Bioética e pandemia de influenza. Rev HCPA. 2009;29(2):161-6.

2. Johns Hopkins University. COVID-19 Dashboard [Internet]. Baltimore; 2020 [citado 15 nov 2020]. Disponível em: https://bit.ly/3obXalX

3. Shannon CE. A mathematical Theory of Communication. Bell Syst Tech J. 1948;27:379-423,623-56.

4. Tucholsky K. Lerne lachen ohne zu weinen. Berlin: Ernst Rowohlt; 1932.

5. White D, Katz M, Luce J, Lo B. Who should receive life support during a public health emergency? Using ethical principles to improve allocation decisions. Ann Intern Med. 2009;150(2):132-8.

6. Rosenbaum L. Facing Covid-19 in Italy: ethics, logistics, and therapeutics on the epidemic's front line. $N$ Engl J Med. 2020;382:1873-5.

7. Pessini L. Distanásia: até quando prolongar a vida? São Paulo: Loyola; 2001.

8. Ropohl G. Technik: ein problem der Philosophie? Philos Nat. 1981;18(4):413.
9. João Paulo II. Donum Vitae: instrução sobre o respeito à vida humana nascente e a dignidade da procriação [Internet]. Vaticano: La Santa Sede; 1987 [citado 10 maio 2021]. Disponível em: https://bit.ly/33x6vSa

10. World Medical Associoation. WMA declaration on euthanasia and physician-assisted suicide [Internet]. Ferney-Voltaire; c2021 [citado 10 maio 2021]. Disponível em: https://bit.ly/2REkwL6

11. Stafford N. Swiss doctors object to new suicide guidance. BMJ. 2018;361:k2661.

12. European Institute for Bioethics. Does the Belgian model of integrated palliative care distort palliative care practice? Brussels; 2005.

13. Orsi C. O escândalo das mortes evitáveis [Internet]. São Paulo: Insituto Questão de Ciência; 2020 [citado 10 maio 2021]. Disponível em: https://bit.ly/3vZfesi

14. Wiebe E, Green S, Wiebe K. Medical assistance in dying (MAiD) in Canada: practical aspects for healthcare teams. Ann Palliat Med. 2021;10(3):3586-93.
15. Hofstede G. Culture's consequences: comparing values, behaviors, institutions and organizations across nations. $2^{\mathrm{a}}$ ed. Thousand Oaks: SAGE; 2001.

16. Anjos MF. Eutanásia em chave de libertação. Bol ICPAS. 1989;7(57):6.

17. Martin LM. Eutanásia e distanásia. In: Conselho Federal de Medicina. Iniciação à bioética. Brasilia DF; 1998. p. 171-92.

18. Pancevski B. Coronavirus is taking a high toll on Sweden's elderly families: blame the government [Internet]. New York: The Wall Street Journal; 2020 [citado 18 jun 2020]. Disponível em: https://on.wsj.com/3o5VnoX

19. Borges L. Por Covid-19, Mandetta e CNJ autorizam sepultamentos sem atestado de óbito Quando não se souber ao certo a causa, morte poderá ser registrada como "provável para Covid-19" [Internet]. Brasília (DF): Veja; 2020 [citado 11 abr 2020]. Disponível em: https://bit.ly/33tUOM9

20. Goldim JR. Bioética: origens e complexidade. Rev HCPA. 2006;26(2):86-92. 